\title{
The Surface Segregation of Copper in Non-oriented Electrical Steels
}

\author{
Darja STEINER PETROVIČ, ${ }^{1)}$ Djordje MANDRINO, ${ }^{11}$ Sanja KRAJINOVIĆ, ${ }^{2)}$ Monika JENKO, ${ }^{1)}$ Milorad MILUN, ${ }^{2)}$ \\ Valter DOLEČEK ${ }^{3)}$ and Martin JERAM ${ }^{4)}$
}

1) Institute of Metals and Technology, Lepi pot 11, 1000 Ljubljana,

2) Institute of Physics, Bijenička 46, 10000 Zagreb, Croatia.

Chemical Engineering, Smetanova 17, 2000 Maribor, Slovenia.

Slovenia. E-mail: darja.steiner-petrovic@guest.arnes.si

3) University of Maribor, Faculty of Chemistry and Slovenia.

4) ACRONI d.o.o., Kidričeva 44, 4270 Jesenice,

(Received on March 28, 2006; accepted on July 14, 2006)

\begin{abstract}
The surface segregation of copper was investigated in laboratory and industrial non-oriented electrical steel sheets containing copper. The cold-rolled samples of Fe-Si-Al alloys were annealed in the temperature range 320-1 $120 \mathrm{~K}$ in the ultra-high-vacuum chamber of a field-emission Auger electron spectrometer, and subsequently characterized by Auger electron spectroscopy (AES).

The $\mathrm{Cu}$ segregation rate was estimated based on the surface concentration of $\mathrm{Cu}$ after annealing at a given temperature. Not surprisingly, the AES analysis showed that the intensity of the surface segregation of copper increased with increasing annealing temperature. However, thermal desorption spectroscopy (TDS) showed that above $770 \mathrm{~K}$ the desorption of $\mathrm{Cu}$ started to reduce the surface concentration of $\mathrm{Cu}$, thus making a reliable estimation of the segregation rate impossible.

During the annealings, in addition to the surface segregation of copper, the surface segregation of alloying and impurity elements was observed as well. Moreover, it appeared that some of these constituents compete for available surface sites. For example, it could be concluded that the surface segregation of copper hindered the surface segregation of carbon in the $\mathrm{Fe}-\mathrm{Si}-\mathrm{Al}$ alloys.
\end{abstract}

KEY WORDS: non-oriented electrical steels; copper; carbon; surface segregation; desorption.

\section{Introduction}

Non-oriented electrical steel sheets are used as the core material of motors and small transformers, and are produced from silicon steel with up to $2 \mathrm{wt} \% \mathrm{Si}$ and up to $1 \mathrm{wt} \% \mathrm{Al}$. The silicon stabilizes the ferritic structure of the steel; however, it also reduces the saturation induction of the steel, and hence its permeability. On the other hand, both silicon and aluminum increase the electrical resistivity of the steel. ${ }^{1,2)}$ Generally, the overall chemical composition determines the properties of silicon steels. In practice, the fact that steel products are routinely manufactured using scrap steel that has been repeatedly recycled ${ }^{3)}$ brings about an overall increase in the impurity concentrations of industrial steels. This is particularly so for copper and tin, though the presence of other impurities, like $\mathrm{Se}, \mathrm{Sb}$ and $\mathrm{As}$, is not negligible. Copper and selenium both influence the morphology of the inclusions in non-oriented electrical steel sheets, and they were found to form copper-selenides and the complex inclusions that contain copper-selenides. ${ }^{4)}$

The optimum magnetic properties of cold-rolled non-oriented electrical steel are achieved by a final annealing of the steel sheets in a controlled gas mixture of wet and dry hydrogen in the temperature range from 970 to $1320 \mathrm{~K}$. The main processes involved in developing a preferred texture and the magnetic properties of non-oriented electrical steels are decarburization, recrystallization and grain growth. ${ }^{1,2,5-7)}$

During the annealing of a steel sheet at elevated temperatures numerous phenomena occur on its surface. One of these is the surface segregation of alloying and impurity elements. Segregation denotes the enrichment of solute or solvent atoms from the bulk of a condensed phase at interfaces and surfaces. Segregation processes require the bulk diffusion of the segregands and, in the short term, segregation may only play a significant role at elevated temperatures. These segregation phenomena influence many surface processes and material properties. ${ }^{8)}$

In this paper we present an experimental study of several $\mathrm{Cu}$-containing industrial and laboratory-produced $\mathrm{Fe}-\mathrm{Si}-\mathrm{Al}$ alloys that revealed new data about the surface segregation of $\mathrm{Cu}$ and other alloy constituents. The study was performed using Auger electron spectroscopy (AES) and thermal desorption spectroscopy (TDS).

\section{Materials and Experimental Procedures}

\subsection{Materials}

The materials used were copper-containing laboratorymanufactured $\mathrm{Fe}-\mathrm{Si}-\mathrm{Al}$ alloys and industrial samples of non-oriented electrical steels. The vacuum-melted alloys were cast into ingots and then hot and cold rolled to a thick- 
Table 1. Chemical composition of the $\mathrm{Fe}-\mathrm{Si}-\mathrm{Al}$ alloys. (wt $\%$ )

\begin{tabular}{|c|c|c|c|c|c|c|c|c|c|c|c|c|}
\hline Alloy & $\% \mathrm{Fe}$ & $\% \mathrm{C}$ & $\% \mathrm{Si}$ & $\%$ Al & $\% M n$ & $\% \mathrm{P}$ & $\% \mathrm{~S}$ & $\% A s$ & $\% \mathrm{Cu}$ & $\% \mathrm{Sb}$ & $\% \mathrm{Sn}$ & $\% \mathrm{O}$ \\
\hline LAB0 & balance & 0.042 & 1.73 & 0.80 & 0.20 & 0.002 & 0.002 & $<0.001$ & 0.01 & 0.0004 & 0.005 & $<0.01$ \\
\hline LAB1 & balance & 0.011 & 1.90 & 0.55 & 0.24 & 0.005 & 0.005 & $<0.001$ & 0.24 & 0.0004 & 0.005 & $<0.01$ \\
\hline LAB2 & balance & 0.009 & 1.86 & 0.46 & 0.24 & 0.005 & 0.005 & $<0.001$ & 0.43 & 0.0006 & 0.003 & $<0.01$ \\
\hline IND1 & balance & 0.023 & 1.68 & 0.24 & 0.24 & 0.010 & 0.002 & 0.010 & 0.33 & 0.0050 & 0.019 & $<0.01$ \\
\hline IND2 & balance & 0.022 & 1.74 & 0.47 & 0.26 & 0.021 & 0.002 & 0.006 & 0.60 & 0.0092 & 0.027 & $<0.01$ \\
\hline
\end{tabular}

ness of $0.5 \mathrm{~mm}$. The cold-rolled sheets were cold-rolled again to a final thickness of $0.1 \mathrm{~mm}$ for the purpose of resistive heating. The typical dimensions of the samples were $15 \mathrm{~mm} \times 5 \mathrm{~mm} \times 0.1 \mathrm{~mm}$. Prior to insertion into the AES spectrometer the samples were metallographically polished.

The chemical composition of the alloys is given in Table 1. One laboratory alloy with a very small amount of copper $(0.01 \mathrm{wt} \%)$ was used for the comparison.

\subsection{Auger Electron Spectroscopy (AES)}

The spectrometer was a VG-Microlab 310F instrument, which was equipped with a Schottky field-emission gun with an electron-beam spot size of $10 \mathrm{~nm}$ and a hemispherical electron-energy analyzer. The spectra were typically taken using a $10-\mathrm{kV}$ electron-beam energy for the excitation of the Auger electrons and were recorded with a fixed retard ratio 4 of the analyzer. The spectrometer was mounted on an ion-pumped, ultra-high-vacuum chamber. The typical pressure during the AES analysis was $10^{-7} \mathrm{~Pa}$, which increased to $10^{-5} \mathrm{~Pa}$ during annealings at $1120 \mathrm{~K}$. A Balzers QMS 200 quadrupole mass spectrometer was used to analyze the residual gas during the experiments.

For the in-situ study of surface segregation in ultra-high vacuum (UHV) the samples were resistively heated to $1120 \mathrm{~K}$ using alternating current. The temperature was monitored with a $\mathrm{NiCr} / \mathrm{Ni}$ thermocouple, which was attached to the sample. The accuracy of the temperature measurement was $\pm 1 \mathrm{~K}$.

After the insertion into the apparatus the surface of the samples was cleaned using Ar-ion sputtering (ion etching) in order to remove impurities adsorbed from the atmosphere.

The clean samples were then annealed and analyzed. The temperature was increased from $320 \mathrm{~K}$ up to $1120 \mathrm{~K}$ in steps of $320 \mathrm{~K}$ and the samples were annealed for $5 \mathrm{~min}$ at a particular temperature. After each heating step the surface concentration of the elements was determined from the measured AES spectra. It is important to point out that the measured spectra showed the cumulative effects of the annealing as there was no intermediate ion etching between the annealing steps.

Another way of determining the surface-segregation rate is by performing an AES analysis during isothermal heating of the sample. In this study a series of isothermal investigations were performed in the range 570-1 $120 \mathrm{~K}$. The time period of an isothermal annealing was up to $40 \mathrm{~min}$. After each isothermal run the sample surface was cleaned by ion etching in order to bring its composition back to the starting point.

The surface concentrations of the segregands were evaluated from differentiated AES spectra, from the peak-topeak ratios (of the segregand in comparison to that of iron).
Table 2. Surface segregation of copper in the $\mathrm{Fe}-\mathrm{Si}-\mathrm{Al}$ alloys.

\begin{tabular}{|l|c|c|c|c|c|}
\hline \multirow{2}{*}{} & \multicolumn{5}{|c|}{ Alloy } \\
\cline { 2 - 7 } & LAB0 & LAB1 & LAB2 & IND1 & IND2 \\
\hline Copper content in the bulk material $\left(w_{\mathrm{Cu}} / \mathrm{w}\right.$ w\%) & 0.01 & 0.24 & 0.43 & 0.33 & 0.60 \\
\hline Onset of copper surface-segregation $(T / \mathrm{K})$ & - & 670 & 670 & 670 & 620 \\
\hline Temp. of maximum Cu surface conc. $(T / \mathrm{K})$ & - & 820 & 820 & 870 & 820 \\
\hline Maximum Cu surface conc. $\left(x_{\mathrm{Cu}} / \mathrm{at} \%\right)$ & - & 4.9 & 11.5 & 5.1 & 8.8 \\
\hline Cu surface conc. at $T=1120 \mathrm{~K},\left(x_{\mathrm{Cu}} / \mathrm{at} \%\right)$ & - & 0.75 & 1.08 & 1.39 & 4.00 \\
\hline
\end{tabular}

Assuming that the Auger peak-height ratio is proportional to the atomic concentration of the analyzed element, the surface concentrations were calculated as follows ${ }^{9,10)}$.

$$
x_{i}^{\mathrm{surf}}=k_{i} \cdot \frac{h_{i}}{h_{\mathrm{Fe}(703 \mathrm{eV})}} .
$$

$x_{i}^{\text {surf }}$ : the surface concentration of the segregand

$k_{i}$ : sensitivity factor related to the segregand and the spectrometer $^{10)}$

$h_{i}$ : the peak height of the segregand.

\subsection{Thermal Desorption Spectroscopy (TDS)}

The thermal desorption measurements were performed in a separate, TDS-dedicated, ultra-high-vacuum chamber equipped with a Balzers quadrupole mass spectrometer and a sample manipulator that allowed for precise temperature control. The samples were heated linearly in the temperature range from room temperature to $1470 \mathrm{~K}$ at a constant heating rate of $0.21 \mathrm{~K} / \mathrm{s}$. The temperature was monitored with a $\mathrm{NiCr} / \mathrm{Ni}$ thermocouple that was spot-welded to the back of the sample. Using mass spectrometer we measured the increase of the partial pressure of copper $(\mathrm{m} / \mathrm{e}=63)$ as a function of temperature.

\section{Results}

\subsection{The Surface Segregation of Copper during Linear Heating}

Two kinds of copper-containing $\mathrm{Fe}-\mathrm{Si}-\mathrm{Al}$ alloys were tested: laboratory produced and of industrial origin. The specimen containing only $0.01 \% \mathrm{Cu}$ served as a reference. Namely, in the temperature range of linear heating, $320-1120 \mathrm{~K}$, this sample showed no $\mathrm{Cu}$ segregation, as judged by AES and TDS. This is in contrast to the samples containing $0.24,0.33,0.43$ and $0.60 \mathrm{wt} \% \mathrm{Cu}$, where segregation was detectable at temperatures higher than $620 \mathrm{~K}$.

The results of the AES analysis of the surface segregation of copper during linear heating of the $\mathrm{Fe}-\mathrm{Si}-\mathrm{Al}$ alloys are given in Table 2. The higher the content of copper in the bulk, the higher was its surface enrichment. With an increasing content of copper in the bulk the width of the temperature interval of its segregation also increased. The sur- 


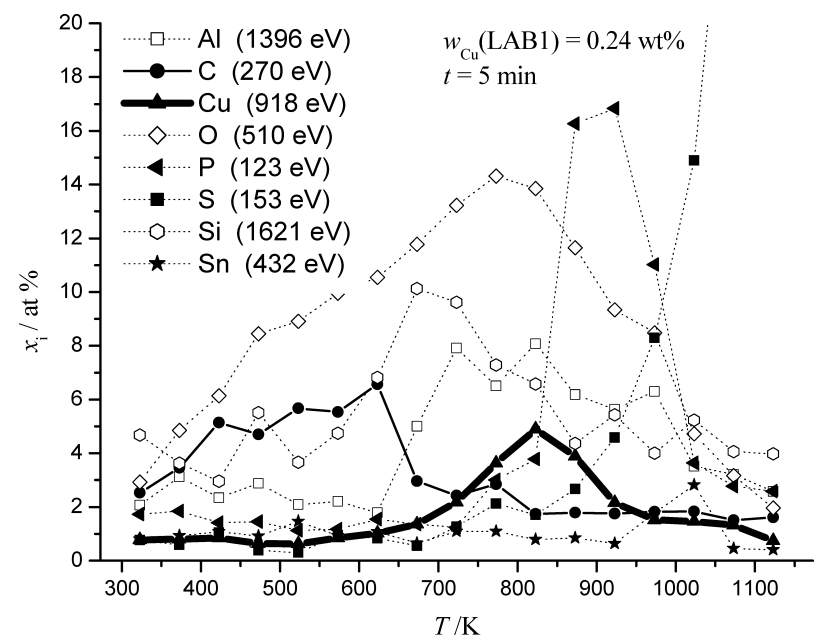

Fig. 1. The surface segregation of elements in a laboratory $\mathrm{Fe}-\mathrm{Si}-\mathrm{Al}$ alloy containing $0.24 \mathrm{wt} \% \mathrm{Cu}$.

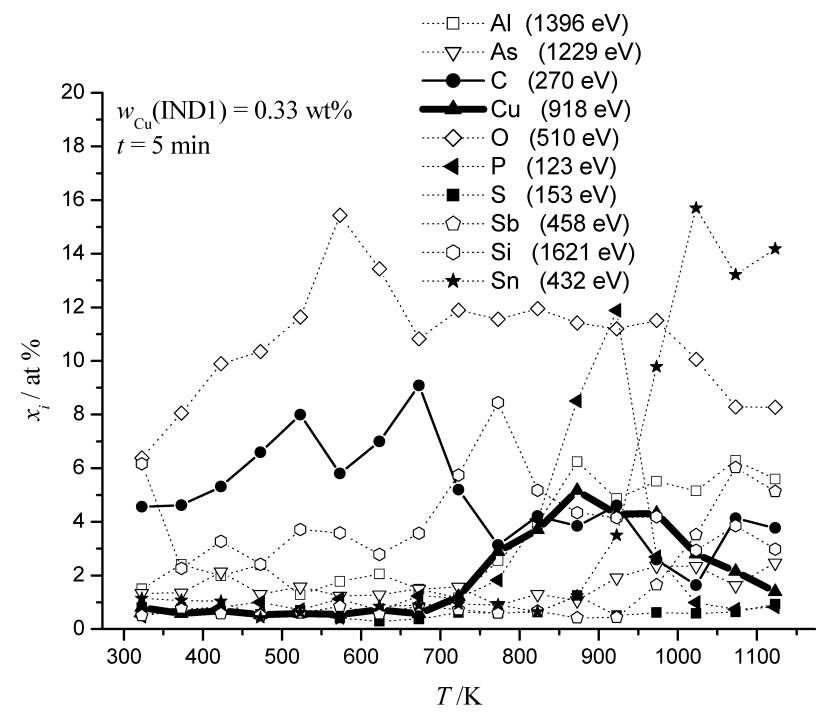

Fig. 2. The surface segregation of elements in an industrial $\mathrm{Fe}-\mathrm{Si}-\mathrm{Al}$ alloy containing $0.33 \mathrm{wt} \% \mathrm{Cu}$.

face segregation of copper reached its maximum values at temperatures $T=820$ and $870 \mathrm{~K}$. After reaching the maximum values the surface concentration of the segregated copper decreased with the increasing temperature of the annealing.

The AES results of two typical samples, the laboratory and industrial, are given in Figs. 1 and 2, respectively. They show the surface concentrations of copper, carbon, silicon, aluminum, oxygen, phosphorus, sulfur, tin, antimony and arsenic as a function of temperature. As can be seen from these two diagrams and Table 1 the surface segregation of the elements depends on the annealing temperature and their bulk concentration. The values given in Table 2, and shown in Figs. 1 and 2, represent the cumulative values of the surface enrichment of the segregands during annealing.

In the $\mathrm{Fe}-\mathrm{Si}-\mathrm{Al}$ alloys containing more than $0.2 \mathrm{wt} \%$ of copper the surface segregation of both oxygen and carbon was detected from the very onset of the annealing. The oxygen surface segregation was present in the whole temperature range of the annealing while carbon concentration reached a maximum at approximately $670 \mathrm{~K}$. At higher temperatures the surface segregation of carbon decreased

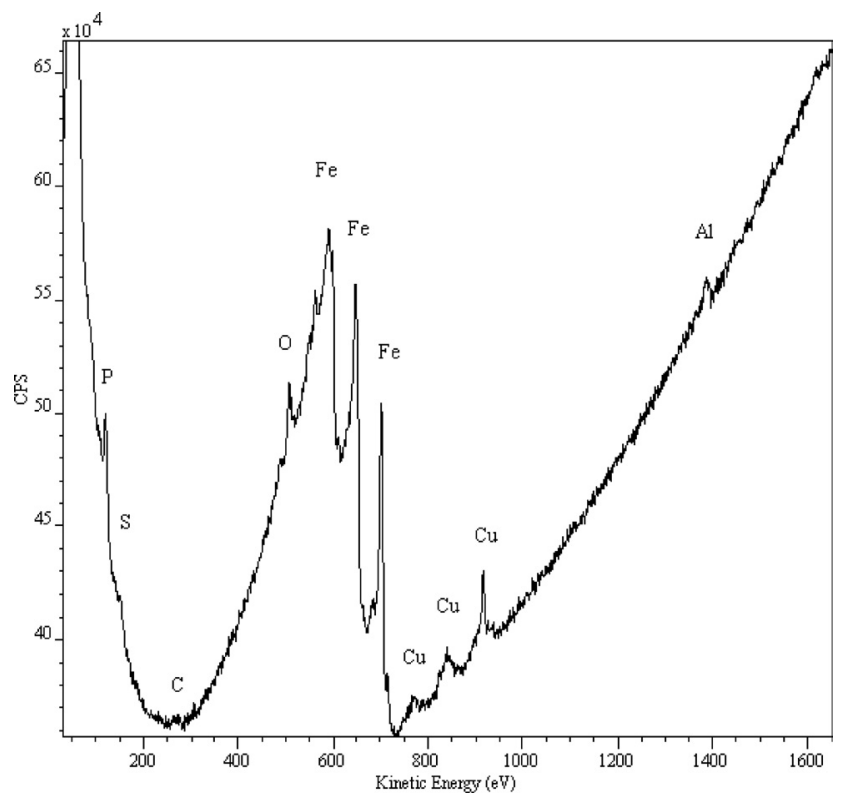

Fig. 3. An AES spectrum for a laboratory alloy containing $0.43 \mathrm{wt} \% \mathrm{Cu}$ (after annealing in UHV at $920 \mathrm{~K}$ for $300 \mathrm{~s}$ ).

(Figs. 1-3). In Fig. 3 a non-differentiated AES spectrum for a laboratory sample containing $0.43 \mathrm{wt} \% \mathrm{Cu}$ is presented. After an annealing at $920 \mathrm{~K}$ the carbon peak $\left(E_{\mathrm{k}}=270 \mathrm{eV}\right)$ decreased to the background level.

On the other hand, the surface segregation of carbon in the reference sample increased in the temperature range $470-1070 \mathrm{~K}$. The surface segregation of carbon decreased at $1120 \mathrm{~K}$, when the surface segregation of the sulfur became more intensive.

The surface segregation of silicon in the $\mathrm{Fe}-\mathrm{Si}-\mathrm{Al}$ alloys increased up to approximately $770 \mathrm{~K}$, and that of aluminum was more intensive at temperatures above $670 \mathrm{~K}$.

The surface segregation of phosphorus started at $720 \mathrm{~K}$. The maximum phosphorus enrichments in the industrial steels were measured at lower temperatures than in the laboratory steels. The peak values for the phosphorus segregation in the industrial steel were reached at $820 \mathrm{~K}$ and $870 \mathrm{~K}$, whereas in the laboratory steel the peak temperature was $920 \mathrm{~K}$.

It can be seen from the chemical composition of the alloys that the laboratory and industrial steels differ very much in their tin and sulfur contents (Table 1). This difference was also obvious in the AES spectra. In the case of industrial steels, tin was predominantly present at the steel's surface at temperatures above $870 \mathrm{~K}$. In the laboratory steels the surface is enriched by sulfur at temperatures above $970 \mathrm{~K}$.

The surface segregation of antimony and arsenic was detectable only in the industrial samples, where the bulk concentration of antimony exceeds a value of $0.005 \mathrm{wt} \%$ and that of arsenic, approximately $0.010 \mathrm{wt} \%$.

The surface segregation of antimony in the industrial steels started at $870 \mathrm{~K}$. It was detectable on the surface up to $1120 \mathrm{~K}$. The AES measurements showed the surface segregation of arsenic at temperatures higher than $1070 \mathrm{~K}$. 


\subsection{The Surface Segregation of Copper during Isothermal Heating}

The typical temperature and time dependence of the intensity of the surface segregation of copper in the $\mathrm{Fe}-\mathrm{Si}-\mathrm{Al}$ alloys containing more than $0.2 \mathrm{wt} \% \mathrm{Cu}$ can be seen from the diagrams in Figs. 4 and 5, where typical results of the laboratory and industrial samples during isothermal annealing are shown. The values given in the diagrams were measured after different times of isothermal annealing at a particular temperature (from 570 to $1120 \mathrm{~K}$ ). The surface of the steel samples was cleaned by ion etching after each isothermal annealing.

The surface segregation of copper was detected in the temperature range $770-970 \mathrm{~K}$ during isothermal annealing after intermediate ion-etching of the steel surface. The highest intensities of the surface segregation of copper in the laboratory alloys were measured at $870 \mathrm{~K}$ and $920 \mathrm{~K}$. The industrial sample with $0.33 \mathrm{wt} \% \mathrm{Cu}$ showed a double peak at $870 \mathrm{~K}$ and $970 \mathrm{~K}$. The maximum intensity of the surface segregation of copper for the industrial sample with $0.60 \mathrm{wt} \% \mathrm{Cu}$ was at $870 \mathrm{~K}$. The most intensive surface segregation of copper occurred in the laboratory sample containing $0.43 \mathrm{wt} \% \mathrm{Cu}$ at $920 \mathrm{~K}$, and in the industrial sample of a $\mathrm{Fe}-\mathrm{Si}-\mathrm{Al}$ alloy containing $0.60 \mathrm{wt} \% \mathrm{Cu}$ at $870 \mathrm{~K}$. The highest enrichment in copper corresponded to approximately $10 \mathrm{at} \% \mathrm{Cu}$ at the surface (alloys containing 0.43 and $0.60 \mathrm{wt} \% \mathrm{Cu}$ ).

Figure 4 shows the surface segregation of copper for the laboratory alloy containing $0.24 \mathrm{wt} \% \mathrm{Cu}$. The maximum of the surface segregation of copper was measured at $870 \mathrm{~K}$, when the intensity of the surface segregation increased with the time of the annealing. Afterwards, the surface enrichments with copper decreased with the temperature and the time of annealing.

Figure 5 shows the surface segregation of copper for the industrial alloy containing $0.33 \mathrm{wt} \% \mathrm{Cu}$. In the diagram we can see a double peak at $870 \mathrm{~K}$ and $970 \mathrm{~K}$. The intensity of the surface segregation of copper increased with time to $970 \mathrm{~K}$, afterwards it decreased with the time and the temperature of annealing.

The surface segregation of copper during isothermal annealing increased with the increasing time and temperature of annealing, reached its maximum values and then decreased with increasing time and temperature.

We also compared the surface segregation of copper and carbon in the alloys during isothermal annealing. The comparison showed that the intensity of the surface segregation of carbon decreased with an increase in the surface segregation of copper. This can be seen from a comparison of Fig. 4 and Fig. 6, where the surface segregations of the copper and carbon for the laboratory $\mathrm{Fe}-\mathrm{Si}-\mathrm{Al}$ alloy containing $0.24 \mathrm{wt} \% \mathrm{Cu}$ are presented.

The temperature of the onset of the surface segregation of copper and the temperature where the maximum values of the surface segregation of carbon were measured overlap in the alloy with $0.24 \mathrm{wt} \% \mathrm{Cu}$. This kind of site competition between the copper and carbon was observed in all the $\mathrm{Fe}-\mathrm{Si}-\mathrm{Al}$ alloys investigated in this study.

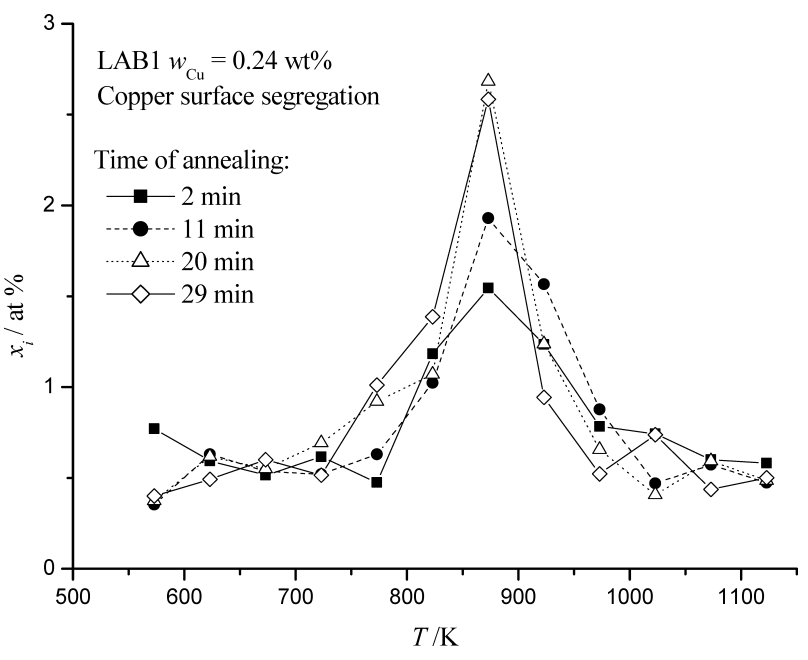

Fig. 4. Surface segregation of copper during isothermal heating in a laboratory alloy containing $0.24 \mathrm{wt} \% \mathrm{Cu}$.

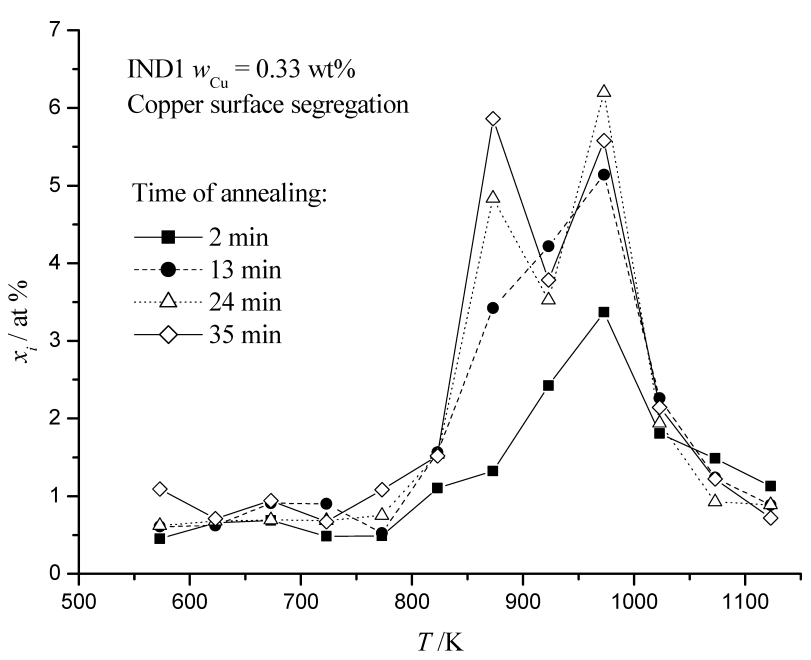

Fig. 5. Surface segregation of copper during isothermal heating in an industrial alloy containing $0.33 \mathrm{wt} \% \mathrm{Cu}$.

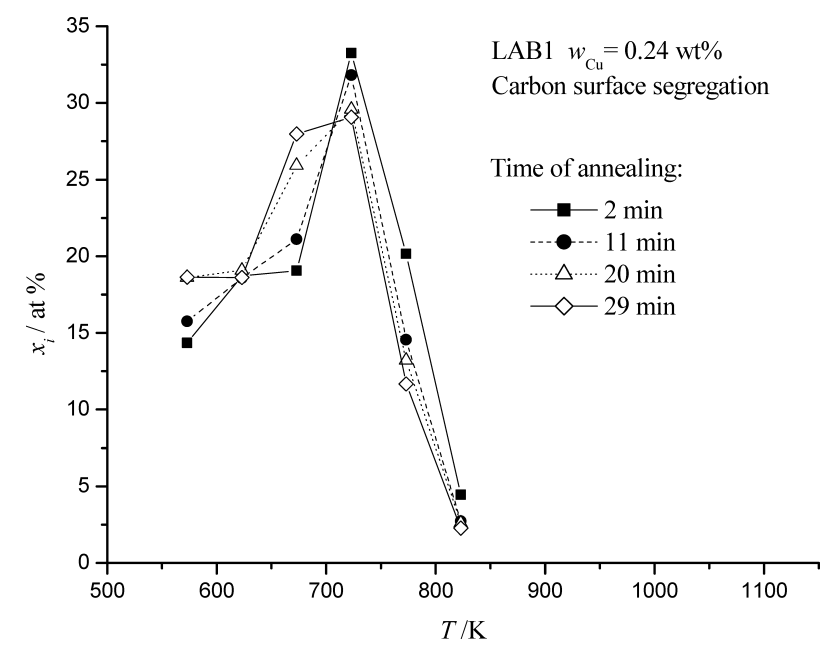

Fig. 6. Surface segregation of carbon during isothermal heating in a laboratory alloy containing $0.24 \mathrm{wt} \% \mathrm{Cu}$.

\subsection{The Thermal Desorption of Copper}

The AES analysis showed that the intensity of the surface segregation of copper first increased and then decreased with an increasing annealing temperature. This could be 


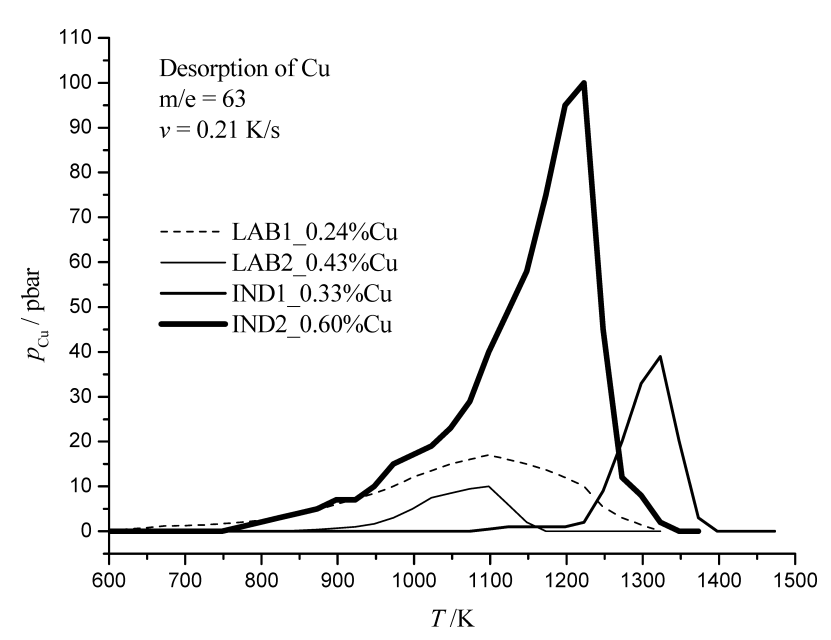

Fig. 7. The thermal desorption spectra of copper in $\mathrm{Fe}-\mathrm{Si}-\mathrm{Al}$ alloys.

seen in Figs. 1-5. Several processes may cause such a behaviour: i) diffusion into the bulk, ii) agglomeration of $\mathrm{Cu}$ into clusters of a size not detectable by AES, and iii) desorption of $\mathrm{Cu}$. Our TDS experiments showed that $\mathrm{Cu}$ desorbed from all the samples, except for the reference one. The onset of desorption was typically above $770 \mathrm{~K}$. The desorption onset, the desorption peak maximum and shape and the end of desorption are generally dependent on the chemical composition of the samples, the surface structure characteristics, the number and size of the grains, their preferential orientation, etc. All of this is reflected in the TD spectra of our samples, as shown in Fig. 7.

The $\mathrm{Cu}$ TDS spectra of all the samples show only one peak and this varies in shape and position from sample to sample. However, the laboratory samples exhibit maxima at lower temperatures (approximately $1100 \mathrm{~K}$ ) than the industrial ones (around $1270 \mathrm{~K}$ ). Most probably, the higher concentration of impurities in the industrial samples hinders the $\mathrm{Cu}$ diffusion to the surface because of an increased number of competing diffusion processes. Interestingly, the TDS spectra of the industrial alloys have the typical lineshape of a zero-order desorption process. In a zero-order desorption process the desorption kinetics does not depend on the surface concentration of the desorbing particle. ${ }^{11)}$ This would imply that the $\mathrm{Cu}$ in the industrial samples indeed agglomerates in either two-dimensional islands or in three-dimensional clusters, whereas desorption took place from the island edge of the cluster surface.

\section{Discussion}

The surface-segregation phenomena in multi-component alloys are very complex. The alloys for non-oriented electrical steel sheets can be produced from $\mathrm{Fe}-\mathrm{Si}-\mathrm{Al}$ alloys that contain many impurity elements. One of these is copper. Our investigation was focused on a determination of the surface segregation of copper in $\mathrm{Fe}-\mathrm{Si}-\mathrm{Al}$ alloys containing different amounts of copper. The AES analysis of the surface segregation during annealing of the $\mathrm{Fe}-\mathrm{Si}-\mathrm{Al}$ alloys in the temperature range $320-1120 \mathrm{~K}$ showed that the elements that segregate to the surface are as follows: aluminum, antimony, arsenic, carbon, copper, oxygen, phosphorus, silicon, sulfur and tin.

The surface segregation of oxygen and carbon in the $\mathrm{Fe}-\mathrm{Si}-\mathrm{Al}$ alloys was detected from the onset of the annealing (Figs. 1-3, 6). The solubility of interstitially dissolved oxygen in $\alpha$-iron is very low, therefore, the surface segregation of oxygen on iron can not be interpreted easily.,12) However, oxygen in the cold rolled samples of $\mathrm{Fe}-\mathrm{Si}-\mathrm{Al}$ alloys can also be present in the form of oxides. The measured surface segregation of oxygen in our study may therefore be of twofold origin: due to the outgassing of the steel in UHV conditions (the outgassing species are primarily hydrogen, carbon monoxide, water, and carbon dioxide) and due to the oxygen segregation from the iron-, aluminumand silicon oxides. Oxygen can also compete for the surface sites with other segregated atoms. Such a competition has already been demonstrated between sulfur and oxygen at the free surfaces of iron. ${ }^{9)}$ In our study this phenomenon was more pronounced in the case of laboratory steels and could be seen from the Fig. 1. The surface segregation of oxygen was also studied by Viefhaus and Grabke ${ }^{12)}$ at $1070 \mathrm{~K}$ on iron single crystals. Their results showed that oxygen segregation on $\mathrm{Fe}(100)$ does not stop at the stage of a $c(2 \times 2)$ structure but continues to a $\mathrm{p}(1 \times 1)$ which is stable at lower oxygen activities and that the transition to three-dimensional $\mathrm{FeO}$ growth can occur at oxygen activities beyond $\mathrm{Fe}-\mathrm{FeO}$ equilibrium.

The analysis of AES results on copper surface segregation showed that the surface segregation of copper in silicon steels depends on the annealing temperature and its bulk content. The more copper in the bulk, the broader is the temperature interval of its segregation. The maximum intensity of the surface segregation of copper was measured at $820 \mathrm{~K}$ and $870 \mathrm{~K}$. After reaching the peak values the copper surface concentrations decreased with an increase in the annealing temperature and time (Figs. 1-5). This indicated the desorption of copper from the surface at higher temperatures. The intensity of the surface segregation of copper was dependent on its bulk content and was not measurable in the $\mathrm{Fe}-\mathrm{Si}-\mathrm{Al}$ alloy containing $0.01 \mathrm{wt} \% \mathrm{Cu}$.

The measured surface values of copper were therefore the sum of at least two processes that occurred during the annealing:

- the surface segregation of copper

- the desorption of copper from the surface.

The copper surface-segregation equilibrium could not be established because of the desorption of segregated copper from the steel surface at elevated temperatures. The preconditions for the equilibrium surface segregation after Grabke $^{13)}$ are:

a) that the segregation equilibrium, atoms (dissolved)= atoms (chemisorbed), is established quickly;

b) that the desorption of the adsorbed species occurs only very slowly;

c) that there is sufficient solubility of the adsorbate in the metal, so that segregation can occur without the depletion of solute atoms.

The process of the surface segregation of copper during the annealing of $\mathrm{Fe}-\mathrm{Si}-\mathrm{Al}$ alloys can be determined by the dynamic equilibrium:

$$
\mathrm{Cu}(\text { dissolved })=\mathrm{Cu}(\text { segregated }) \rightarrow \mathrm{Cu}(\text { desorbed })
$$


The desorption of segregated copper from the surface began at temperatures higher than $770 \mathrm{~K}$. The measured TDS spectra for the industrial samples showed a typical zero-order desorption (Fig. 7). According to the PolanyiWigner equation

$r_{\text {des }}=\left(v \Theta^{n} / v\right) \exp \left(-\Delta E_{\text {des }} / R T\right)$ the desorption rate is expressed by a rate law of the $n^{\text {th }}$ order. ${ }^{11,14)}$ Typical systems, known from the literature, showing a zero-order desorption kinetics are adsorbates of metal atoms from the metal substrates. $^{14-17)}$

The maximum temperature of the desorption in the laboratory alloys was $1100 \mathrm{~K}$, and in the industrial alloys it was $1220 \mathrm{~K}$ and $1320 \mathrm{~K}$. The shifts in the maximum desorption temperature in the zero-order TDS spectra could be associated with the increasing of the coverage ${ }^{11,14)}$ or the presence of other atoms on the surface. Namely, the presence of coadsorbed oxygen in the system $\mathrm{O} / \mathrm{Cu} / \mathrm{Ru}(0001)$ caused modified $\mathrm{Cu}$ distribution and the shifts in desorption spectra of copper. ${ }^{15)}$ We assume therefore that the shifts in TD spectra could be the result of the interactions among the segregated copper and the other elements of the alloying system, both, segregated and in the solid solution.

The comparison of the surface segregation of copper and carbon in the investigated alloys showed that the intensity of the surface segregation of carbon decreased with an increase in the surface segregation of copper (Figs. 1-4 and $6)$. The temperature at the beginning of the surface segregation of copper and the temperature where the maximum values of the surface segregation of carbon were measured were found to overlap. This we interpret as a site competition between the copper and the carbon that we observed in all the investigated $\mathrm{Fe}-\mathrm{Si}-\mathrm{Al}$ alloys. A similar competition between the copper and the carbon was also observed in a recent study of the decarburization of laboratory $\mathrm{Fe}-\mathrm{Si}-\mathrm{Al}$ alloys containing copper. ${ }^{7)}$ The results of that study have shown that the decrease of the initial carbon content was the highest in the alloy with the lowest amount of copper. This implies that $\mathrm{Cu}$ blocked the surface sites for carbon, thus reducing the decarburization process.

\section{Conclusions}

We measured the surface segregation of copper in alloys for non-oriented electrical steel sheets. The surface segregation of copper in $\mathrm{Fe}-\mathrm{Si}-\mathrm{Al}$ alloys was dependent on the annealing temperature and its bulk content. The maximum intensities of the surface segregation of copper were measured at $820 \mathrm{~K}$ and $870 \mathrm{~K}$. Afterwards, the desorption of the segregated copper from the surface began. The desorption kinetics of the segregated copper was typical for desorption of adsorbed metal atoms from metallic substrates.

From the comparison of the AES results we can conclude that copper has an influence on the surface segregation of the carbon in the $\mathrm{Fe}-\mathrm{Si}-\mathrm{Al}$ alloys. Furthermore, the surface segregation of the carbon was hindered by the surface segregation of copper.

\section{Acknowledgement}

The work was supported by Slovenian project grants from the Ministry of Higher Education, Science and Technology and Acroni d.o.o., Jesenice.

\section{REFERENCES}

1) G. Lyudkovsky, P. K. Rastogi and M. Bala: JOM-J. Miner. Met. Mat., 38 (1986), 18.

2) F. Ronin: Book of Steel, ed. by G. Beranger, G. Henry, G. Sanz, Intercept Ltd., Andover, (1996), 1056.

3) K. Noro, M. Tageuchi and Y. Mizukami: ISIJ Int., 37 (1997), 198.

4) D. Steiner Petrovič and M. Jenko: Vacuum, 71 (2003), 33.

5) G. M. Michal and J. A. Slane: Metall. Trans. A, 17A (1986), 1287.

6) K. M. Marra, E. D. A. Alvarenga and V. T. L. Buono: ISIJ Int., 44 (2004), 618

7) D. Steiner Petrovič, M. Jenko and V. Doleček: Mater. Technol., 40 (2006), 13.

8) C. Uebing: Heterogen. Chem. Rev., 3 (1996), 351.

9) D. Briggs and M. P. Seah: Practical Surface Analysis, 2nd ed., Vol. 1, John Wiley \& Sons, Chichester, (1994), 201, 335.

10) VG Scientific: Technical Documentation, Microlab 310-F, Operators Manuals, VG Scientific Thermo Electron Corporation, East Grinstead, (1997) and (2004).

11) K. Christmann: Introduction to Surface Physical Chemistry, Steinkopff Verlag, Darmstadt, (1991), 159.

12) H. Viefhaus and H. J. Grabke: Surf. Sci., 109 (1981), 1.

13) H. J. Grabke: Scr. Metall., 9 (1975), 1181.

14) K. Nagai: Surf. Sci., 176 (1986), 193.

15) K. Kalki, H. Wang, M. Lohmeier, M. Schick, M. Milun and K. Wandelt: Surf. Sci., 269/270 (1992), 310.

16) S. H. Payne, H. J. Kreuzer, A. Pavlovska and E. Bauer: Surf. Sci., 345 (1996), L1.

17) R. Wagner and K. Christmann: Surf. Sci., 429 (2000), 55. 